\title{
Study of polyamide- 6 hollow fiber membranes prepared via a thermally induced phase-separation method
}

\author{
Zhao-Hui Jiang, ${ }^{1}$ Chang-Fa Xiao, ${ }^{1,2 *}$ Xiao-Yu $\mathrm{Hu}^{2}$ \\ ${ }^{*}$ Department of Materials Science and Chemical Engineering, Tianjin Polytechnic \\ University, Tianjin 300160, China; fax: 022- 24528001, e-mail: xiaocf@yahoo.cn. \\ ${ }^{2}$ Key Laboratory of Hollow Fiber Membrane Materials and Membrane Process of \\ Ministry of Education, Tianjin Polytechnic University, Tianjin 300160, China.
}

(Received: 30 October, 2009; published: 27 March, 2010)

\begin{abstract}
Hollow fiber membranes of polyamide-6(PA6) with porous structure were prepared by a thermally induced phase-separation method. N-Ethyl-o/p-toluene sulfonamide was chosen as diluent. On the basis of scanning electron microscopy (SEM) images, porosity, bubble point pore diameter and pure water flux, the influential factors including polymer concentration, coagulation bath temperature, post-stretching were investigated. The results indicate that with the increasing of PA6 concentration 'slit-shaped' pores in inner surfaces and cellular structure in cross-sections disappear, correspondingly, the properties of membranes such as porosity and pure water flux become poor. As the coagulation bath temperature varied from $20{ }^{\circ} \mathrm{C}$ to $50^{\circ} \mathrm{C}$, the pure water flux of membranes is improved from 136 to $244 \mathrm{~L} \cdot \mathrm{m}^{-2} \cdot \mathrm{h}^{-1}$. Post-stretching make the 'interfacial micro-pores' expand due to 'stress concentration' phenomenon, thus changing the structure and improving the properties of membranes. PA6 hollow fiber membranes with rational structure and high performance could be obtained by altering polymer concentration, coagulation bath temperature and post-stretching.
\end{abstract}

Keywords: Thermally induced phase-separation; hollow fiber membrane; polyamide-6(PA6); post-stretching; interfacial micro-pores

\section{Introduction}

Polyamide-6(PA6) is a type of engineering thermoplastic material owing to its good chemical stability, good biocompatibility and outstanding strength, now considered as a promising membrane material. Some literatures indicate that PA6 membrane is an ideal choice for nanofiltration (NF) and osmosis reversal (OR) process [1]. Porous aliphatic polyamide flat membranes have been commercialized for many years and nowadays widely used in fine separation processes such as beverages and alcohol sterilization, pharmaceutical and various solvent filtration. However, commercial aliphatic polyamide flat membranes are often manufactured by a common 'phase inversion' process, in which formic acid serves as solvent [2]. In view of the corrosion of acid to equipment and difficulties in forming process, PA6 is seldom used in hollow fiber membranes. In this paper, PA6 hollow fiber membranes were prepared by the thermally induced phase-separation method.

Since the thermally induced phase separation (TIPS) method was first used by Castro in the1980s [3], this method has been studied extensively for the preparation of membranes. In the 1990s, Lloyd and co-workers systematically studied the phaseseparation mechanism, determining the factors of the TIPS method. [4-5]. Nowadays, the studies on influential factors in TIPS process are intensified [6-9]. A wide variety 
of polymer membranes can be obtained via TIPS method [10-12].This process gained much interest because of its advantages over other conventional membrane preparation methods such as solvent casting, stretching, and track etching. The TIPS process, applicable to a wide range of polymers including polypropylene, polyethylene and poly(vinylidene fluoride), requires few parameters in determining the porous structure. Matsuyama further investigated the TIPS method both in influential factors and control of the porous structure in different systems [13].

PA6 has strong intermolecular hydrogen bonding and no suitable solvent at room temperature. Therefore, $\mathrm{N}$-ethyl-2/4-methylbenzenesulfonamide was chosen as diluent. In addition, membranes prepared by the TIPS method have incomparable advantages including better mechanical properties, better pore structure and higher porosity. On the basis of scanning electron microscopy images, porosities, bubble point pore diameter and pure water flux, the influential factors including polymer concentration, coagulation bath temperature, post-stretching were investigated.

\section{Results and discussion}

\section{Effect of polymer concentration}

The surfaces and cross-section morphologies are, respectively, shown in Fig. 1, Fig. 2 and Fig. 3.

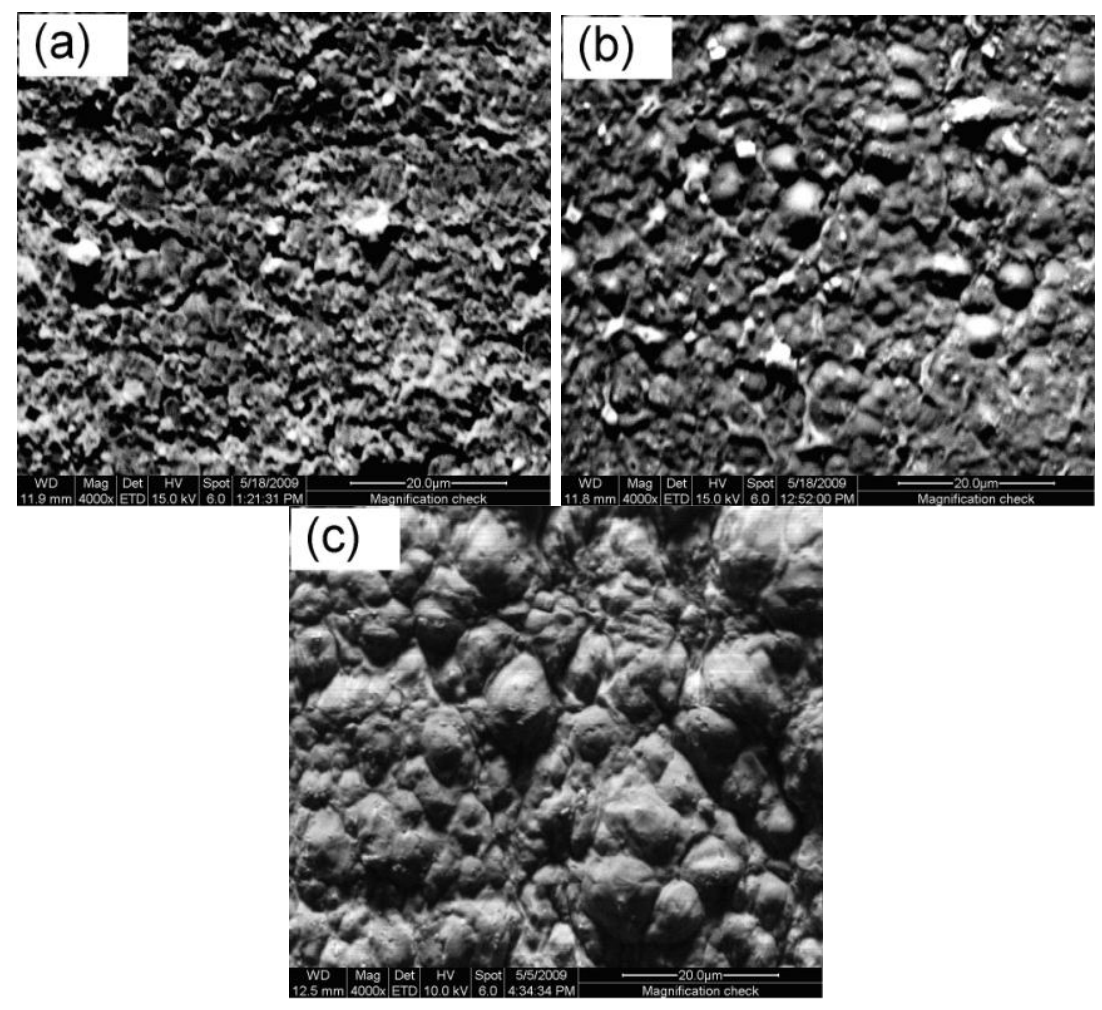

Fig. 1. Scanning electron micrographs (SEM) from the inner surface-(a) $S 1$ (b) S3 (c) S4.

A comparison of Fig. 1(a, b, c) can lead to the conclusion that the pore size decreases with the increase of polymer concentration. Furthermore, large ballshaped cluster aggregates appear in the inner surface (see Fig. 1(c)). When the polymer concentration increases, the polymer-lean phase decreases, and the 
increasing viscosity restrains the coarsening process. Therefore, the pore size decreases. In addition, the images of inner and outer surface indicate that the membranes have an asymmetric structure. The inner surfaces, with a great deal of 'slit-shaped' pores in low PA6 concentration and 'large ball-shaped cluster aggregates' structure caused by high concentration, have greater differences. While the outer surfaces show spherulitic morphology, no micro-pores could be found under SEM. In Fig. 3 (a) and (b), cellular structure is clearly presented, that is, polymer matrix is composed of small crystallite particle and the micro-pores could be directly observed.

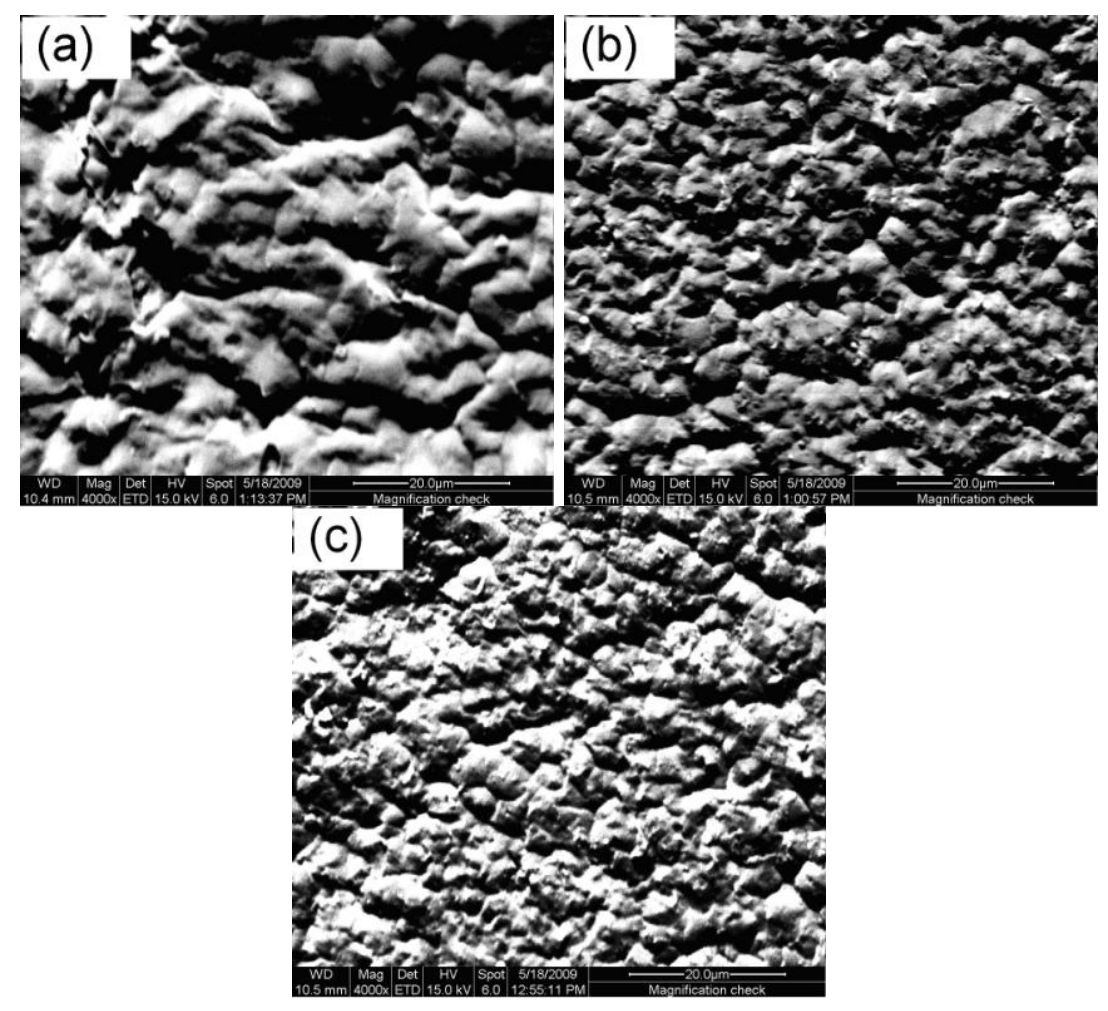

Fig. 2. Scanning electron micrographs (SEM) from the outer surface -(a) S1 (b) S3 (c) S4.

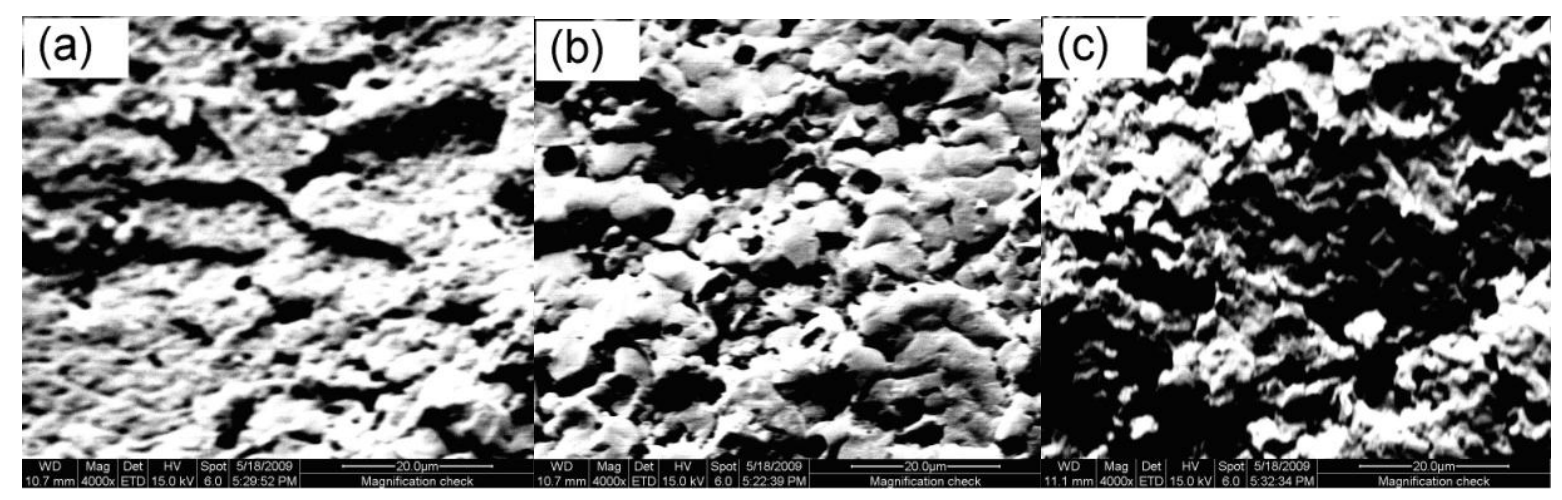

Fig. 3. Scanning electron micrographs (SEM) from the cross-section-(a) S1 (b) S2 (c) S3. 


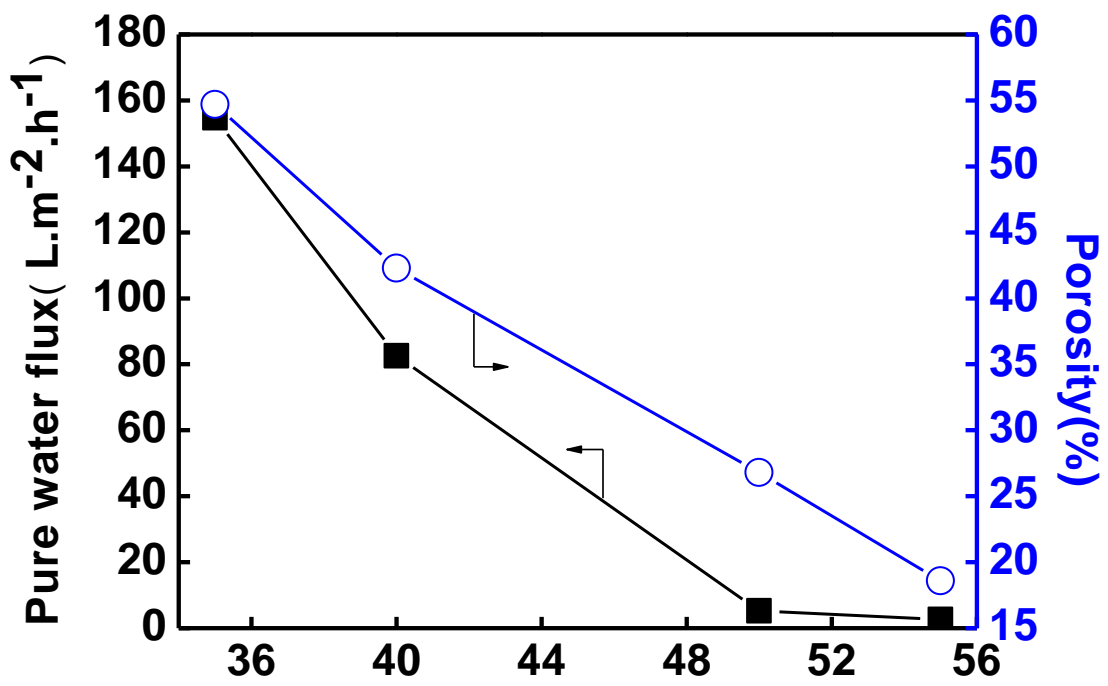

The weight ratio of PA6 in PA6/diluent system(\%)

Fig. 4. Effect of polymer concentration on pure water flux and porosity.

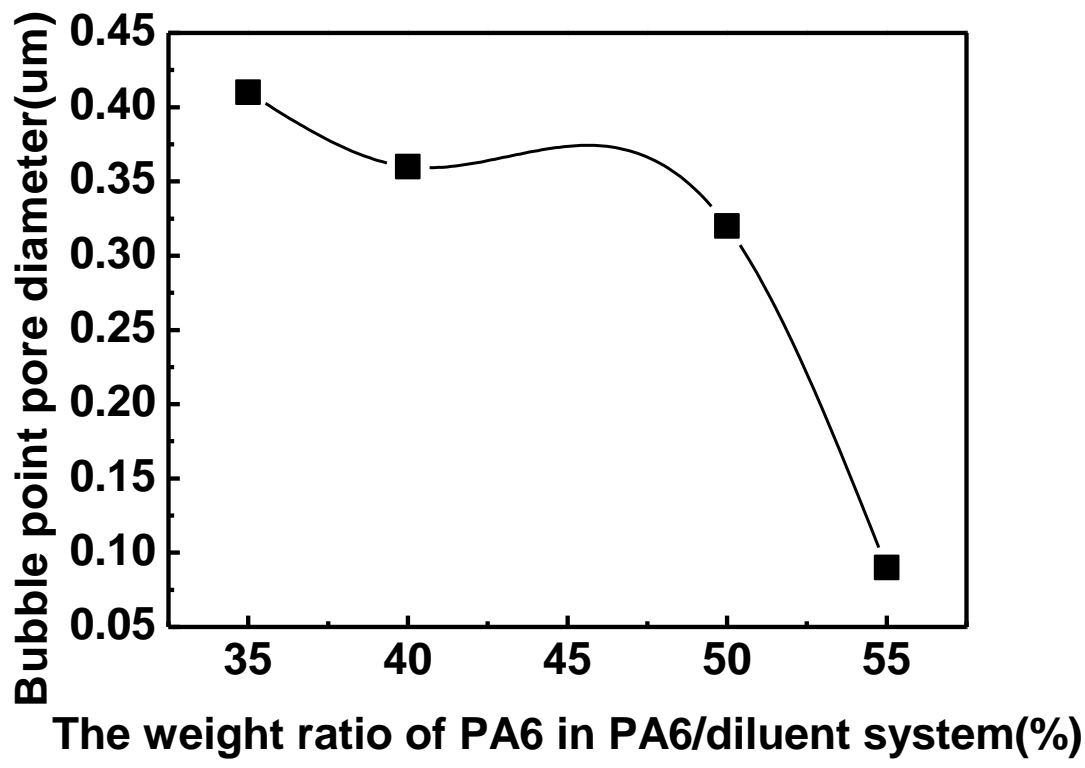

Fig. 5. Effect of polymer concentration on bubble point pore diameter.

In Fig. 3 (c), though micro-pores are clearly visible, big hole defects appear. Exactly speaking, with the polymer concentration increasing the hole defects become significant. For S1 and S2, the surfaces are looser and the cross-sections show typical cellular structure. For S4 (not given) though the cross-sections have big holes, the structure of surface is compacter, so their pure water flux and porosity are much smaller than that of $\mathrm{S1}$, which can be seen in Fig. 4. The effect of polymer concentration on bubble point pore diameter is shown in Fig. 5. It can be seen that 
bubble point pore diameter decreases with the increasing of the polymer concentration, which is not difficult to understand and intuitive to be seen from SEM.

\section{Effect of coagulation bath temperature}

Fig. 6 and Fig. 7 clearly illustrate the strong effect of coagulation bath temperature on morphology when the S1 was taken as investigated subject.
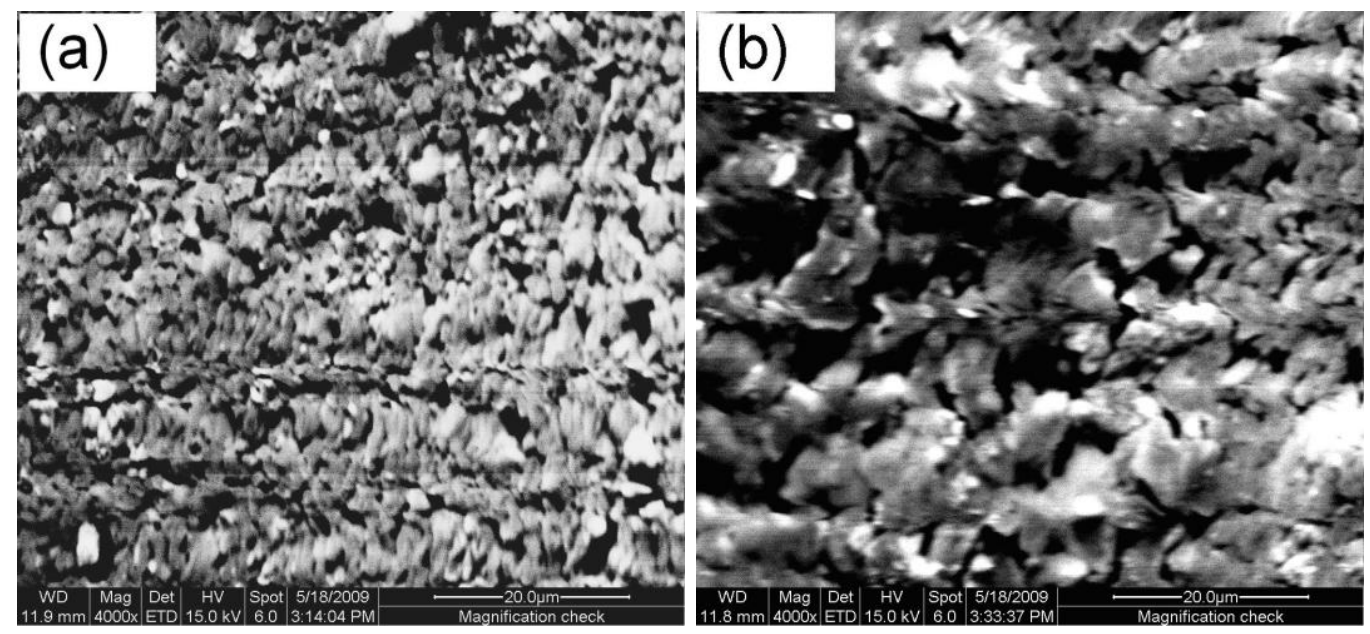

Fig. 6. Effect of coagulation bath temperature on the inner surface morphology of membrane $\left(\mathrm{a}-20{ }^{\circ} \mathrm{C}, \mathrm{b}-50{ }^{\circ} \mathrm{C}\right)$.
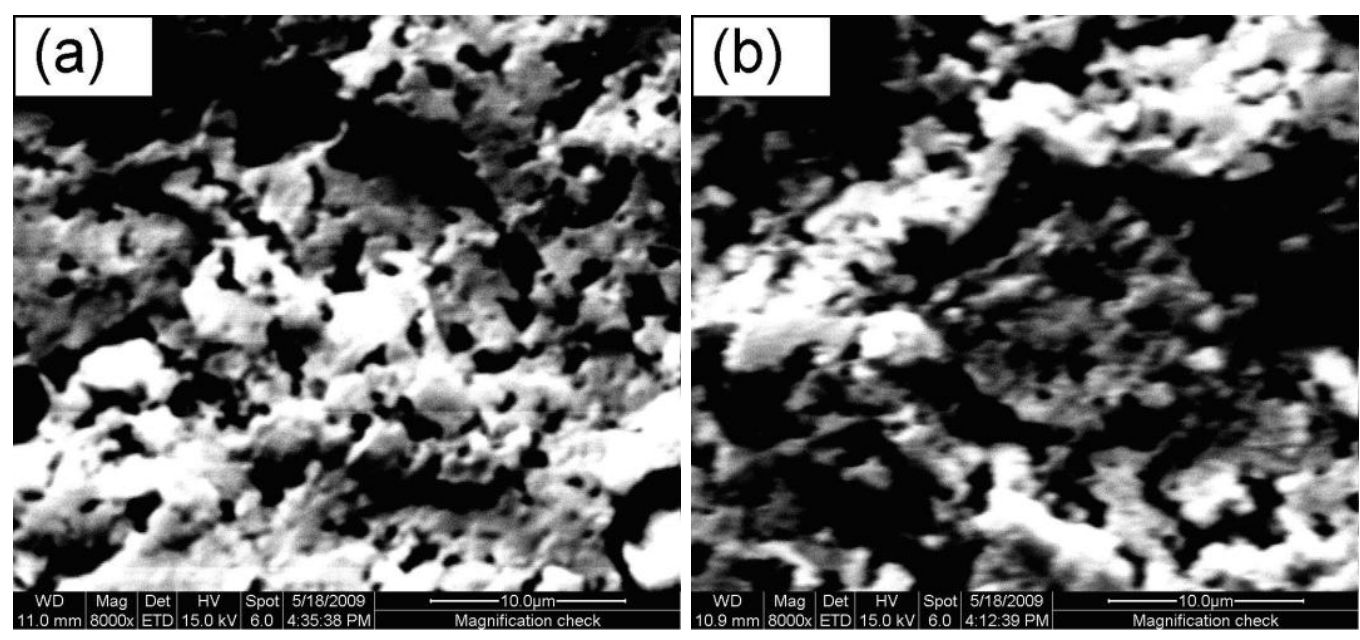

Fig. 7. Effect of coagulation bath temperature on the cross-section morphology of membrane $\left(\mathrm{a}-20{ }^{0} \mathrm{C}, \mathrm{b}-50{ }^{\circ} \mathrm{C}\right)$.

With the coagulation bath temperature increasing, bigger micro-pores appeared in the inner-surface of membrane (Fig. 6). The 'cellular structure' was obviously visible and the connectivity between them was greatly improved (Fig. 7). Different cooling temperatures have a significant impact on the growth of diluent droplets and polymer crystallization [16-19], thus affecting the morphology of membrane. In the case of low coagulation bath temperature, the polymer solution temperature dropped suddenly and the diluent became very viscous before polymer crystallization. This seriously hindered the crystallization of polymer which increased nucleation density and decreased grain size. Correspondingly, the gap which formed micro-pores after 
extraction was small. Furthermore, during the quick cooling process, polymer solution underwent short phase separation, so polymer and diluent phase did not have enough time to coarsen and coalesce. Therefore, the membranes formed at low cooling temperature were endowed with small pore size, low porosity and low pure water flux, which were presented in Tab. 1.

Tab. 1. Effect of coagulation bath temperature on membrane properties.

\begin{tabular}{lccc}
\hline $\begin{array}{l}\text { coagulation bath } \\
\text { temperature } /{ }^{\circ} \mathrm{C}\end{array}$ & $\begin{array}{c}\text { porosity } \\
\%\end{array}$ & $\begin{array}{c}\text { bubble point pore diameter } \\
\mu \mathrm{m}\end{array}$ & $\begin{array}{c}\text { pure water flux } \\
\mathrm{L} \cdot \mathrm{m}^{-2} \cdot \mathrm{h}^{-1}\end{array}$ \\
\hline $20{ }^{0} \mathrm{C}$ & 56.4 & 0.37 & 136 \\
$50{ }^{0} \mathrm{C}$ & 59.1 & 0.54 & 244
\end{tabular}

\section{Effect of post-stretching}

To obtain PA6 hollow fiber membranes that had a higher pure water flux and rational structure, PA6 hollow fiber membranes were drawn under room temperature. The morphologies of membranes modified with $150 \%$ draw ratio are shown in Fig. 8 and Fig. 9. Many crystal spheres could be observed in SEM pictures of the outer surface of original hollow fiber membranes (see Fig. 8 (a)). After drawing, crystal spheres become larger, so as the gap between them. This may be attributed to drawinginduced crystallization. Besides, the peak temperature in DSC curves and degree of crystallinity both rise, which can be seen in Fig. 10and Fig. 11. Also, PA6 hollow fiber membranes have quite different inner and outer surfaces regardless of before or after drawing.
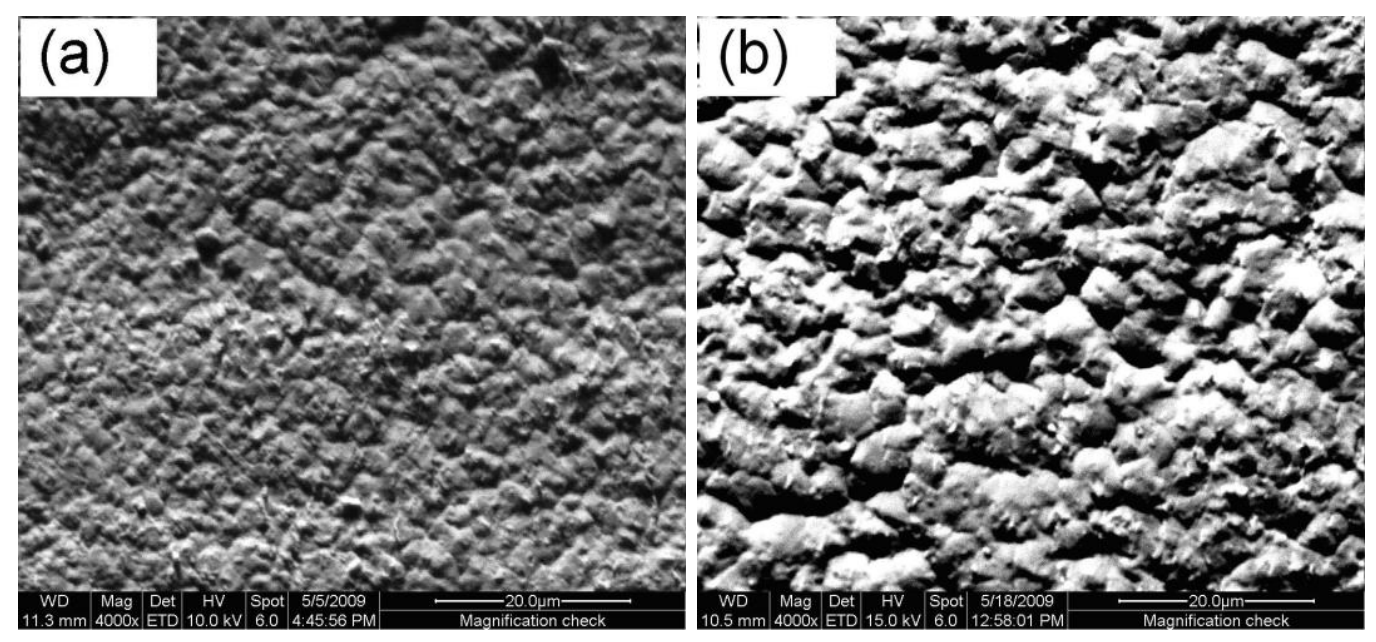

Fig. 8. Effect of post-stretching on outer surface morphology of membrane (aundrawn, b-drawn).

The morphological differences can be explained by the temperature differences between inner and outer surfaces during cooling process [20]. After PA6/ diluent homogeneous solution was squeezed out from the spinneret, firstly through a certain length of air gap, then the outer surface of hollow fiber contacted directly with cooling water, while the inner surface contacted with warm white oil, which was heated by the hot spinneret, this led to the smaller crystal spheres in inner surface than those in outer surface. 

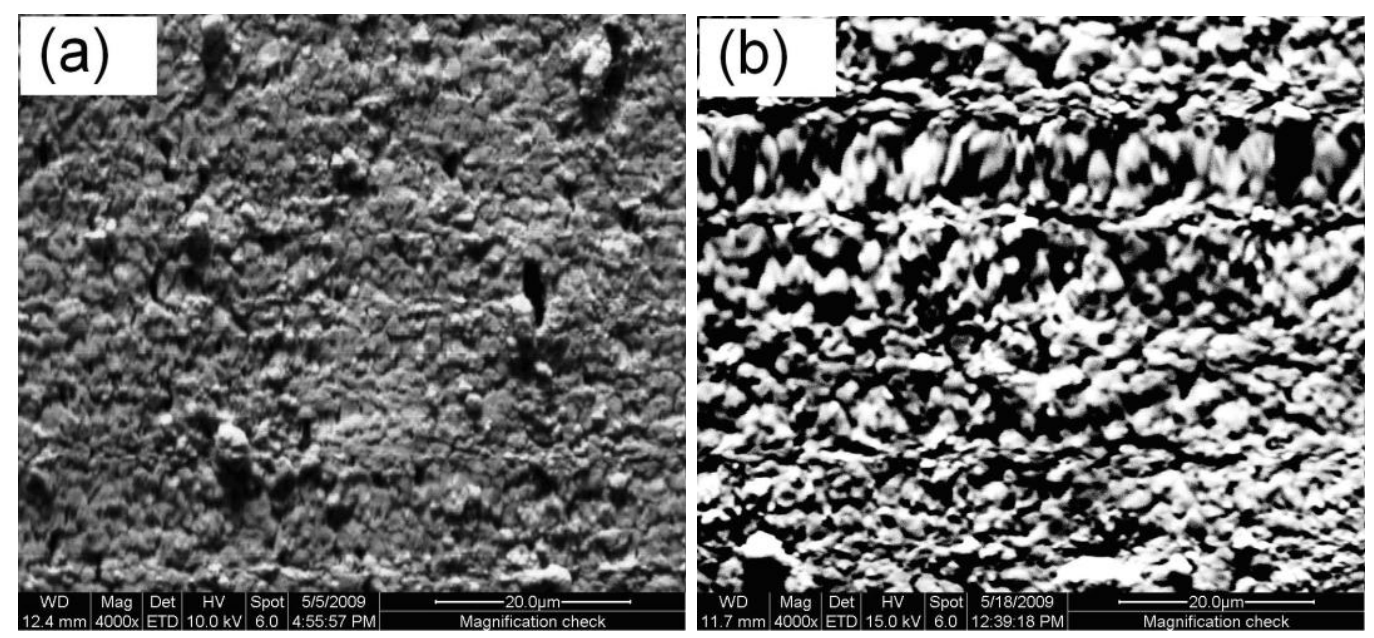

Fig. 9. Effect of post-stretching on the inner surface morphology of membrane (aundrawn, b-drawn).

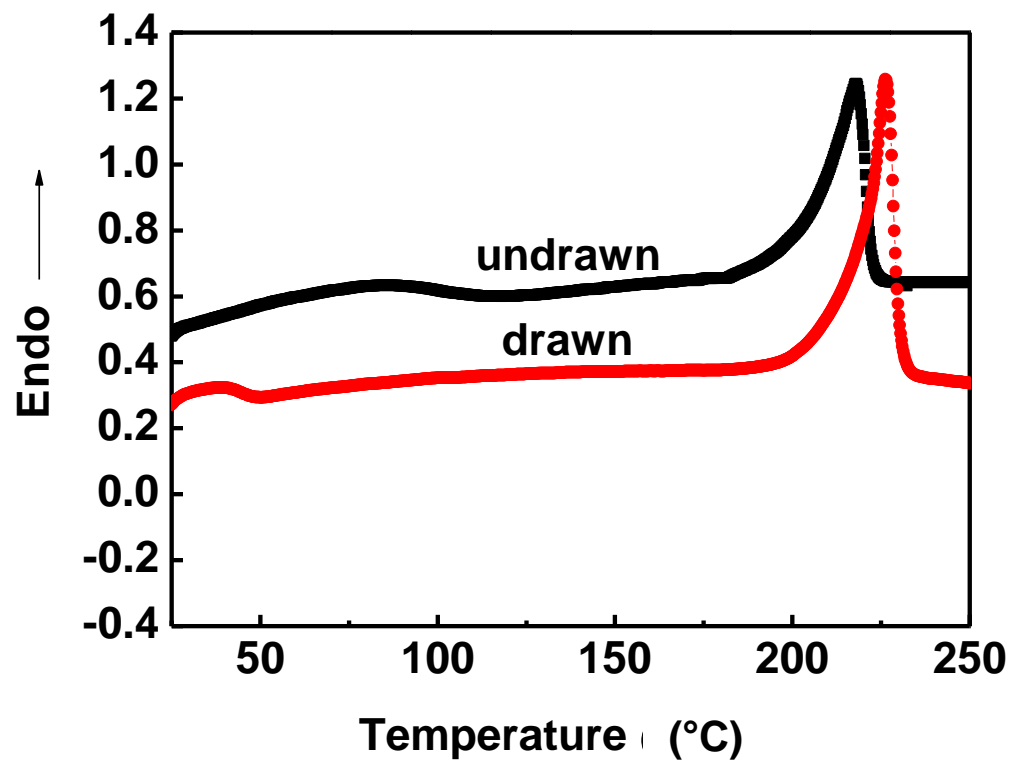

Fig. 10. DSC heating curves of S4 membranes.

In addition, the crystal structure of inner surface is incomplete. A large number of 'interfacial micro-pores' are present in inner surfaces (see Fig.10 (a)), which arises from the surface energy differences between $\mathrm{Nano}_{-} \mathrm{CaCO}_{3}$ and PA6. It is probative that the existence of interface is beneficial to the formation of 'interfacial micro-pores' in many literatures [21-22]. After drawing, many 'comb-shaped micro-pores' appear in inner surfaces (see Fig. 9 (b)), which is specific to drawing-induced membranes. 




Fig. 11. The crystallinity changes of membranes before and after drawing.

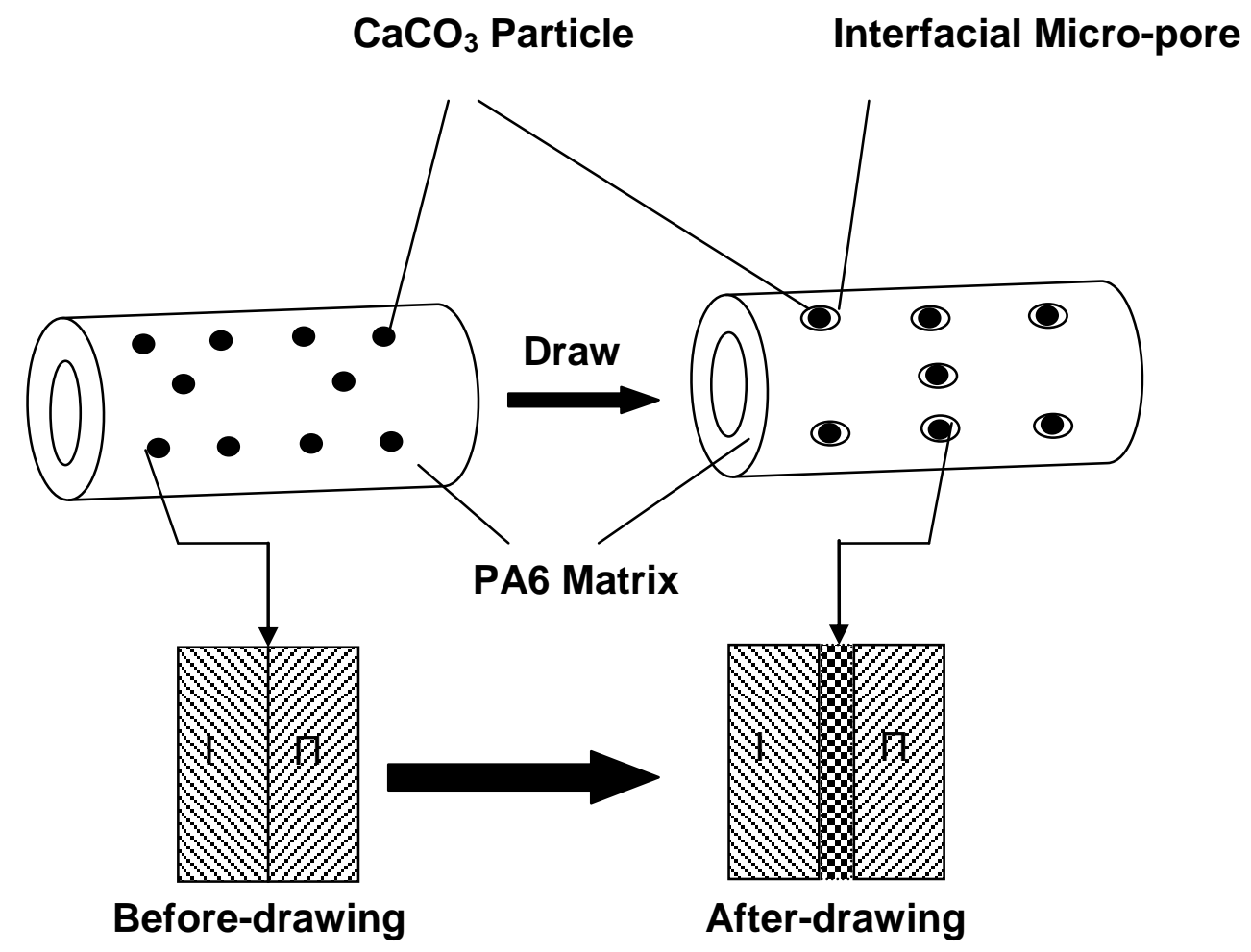

Fig. 12. Schematic diagram of interfacial micro-pores formation.

Ultimately, the formation of the micro-pores can be attributed to the following mechanism: On one hand, PA6 is semi-crystalline polymer, in which there exists lots of crystalline and amorphous region. During the drawing process, amorphous region was over-drawn and formed micro-pores due to partial fracture. While crystalline 
region still held as the skeleton of micro-pores area. On the other hand, in the role of draw-stress, interfacial region expanded as a result of 'stress concentration' phenomenon. Schematic diagram of interfacial micro-pores formation is shown in Fig.12. Therefore, pure water flux of membranes after drawing is greatly improved (see Fig.13).

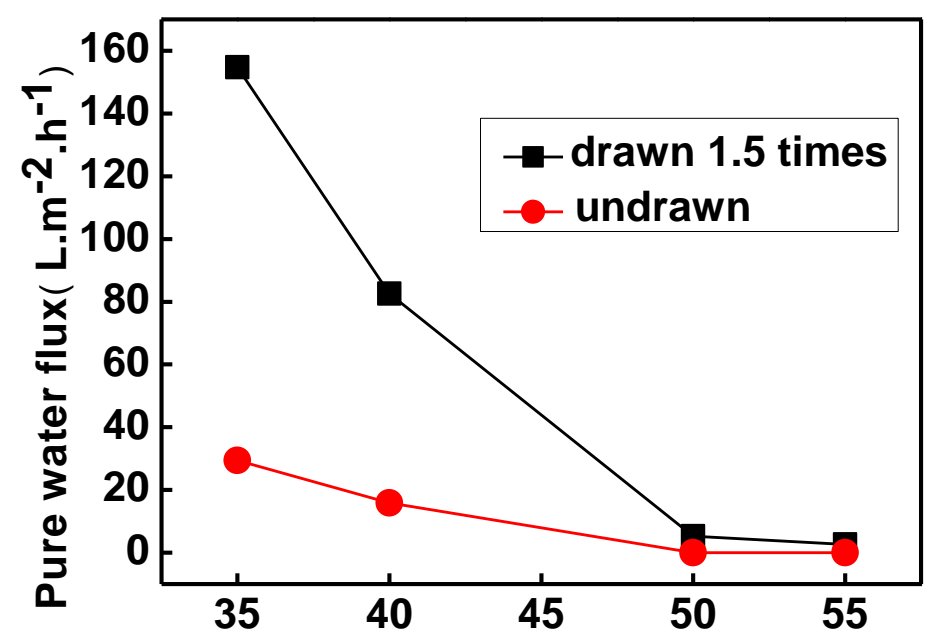

The weight ratio of PA6 in PA6/diluent system(\%)

Fig. 13. Effect of post-stretching on pure water flux of membranes.

\section{Conclusions}

PA6 hollow fiber membranes were prepared via a thermally induced phaseseparation method. The polymer concentration has a significant impact on morphologies and performances of the membrane. For rational structure and excellent performance, PA6 concentration should be controlled in interval $35 \%-55 \%$. The tenacity of membranes is extremely poor, when PA6 concentration is lower than $35 \%$. However, when it is higher than $55 \%$, the membranes almost have no water flux. The coagulation bath temperature is another influencing factor. As the coagulation bath temperature increased from $20{ }^{\circ} \mathrm{C}$ to $50{ }^{\circ} \mathrm{C}$, the porosity and bubble point pore diameter of membranes are both increasing, thus the pure water flux improved sharply from $136 \mathrm{~L} \cdot \mathrm{m}^{-2} \cdot \mathrm{h}^{-1}$ to $244 \mathrm{~L} \cdot \mathrm{m}^{-2} \cdot \mathrm{h}^{-1}$. Post-stretching is an essential process for ideal membranes. After drawing, many 'comb-shaped micro-pores' appear in inner surfaces, meanwhile, the 'interfacial micro-pores' occur and expand for the existence of Nano- $\mathrm{CaCO}_{3}$. Subsequently, the pure water flux of membranes multiplies. Therefore, PA6 hollow fiber membranes with rational structure and high performance could be obtained by altering polymer concentrations, coagulation bath temperature and post-stretching.

\section{Experimental part}

\section{Materials}

Commercial PA6 from Tian He Chemical Fiber Co., Ltd., Tianjin, China, spinninggrade, was received in pellet form. N-Ethyl-2/4-methylbenzenesulfonamide used as 
diluent was purchased from Jin Li Chem. Co., Ltd. Jiaxing, China. Nano- $\mathrm{CaCO}_{3}$ was obtained from Yaohua Nano-Technology Co., Ltd., Shanghai,China. Antioxidant 1076 was supplied by Li Sheng Chemical Plant, Tianjin, China. White oil was commercial product of Zhenda Chemical Co., Ltd., Tianjin, China. All the other reagents were obtained from Keruisi Fine Chemical Co., Ltd., Tianjin, China, which were of analytical grade, and used without further purification.

\section{Membrane preparation}

Prior to using, both $\mathrm{PA} 6$ and $\mathrm{Nano}-\mathrm{CaCO}_{3}$ were dried in vacuum drying oven at 100 ${ }^{0} \mathrm{C}$ for about 6 hours. First, diluent followed by $\mathrm{Nano}^{-} \mathrm{CaCO}_{3}$ were put in a kettle equipped with an electric heating apparatus. After $\mathrm{Nano}_{-} \mathrm{CaCO}_{3}$ was dispersed in diluent for about half an hour, PA6 accompanied with extremely little antioxidant 1076 was plunged into the kettle. Then, the blends were heated to $210^{\circ} \mathrm{C}$, at which they became homogeneous solution. After stabilizing for about half an hour, bubbles in the homogeneous solution were removed in virtue of a vacuum pump. Subsequently, homogeneous solution was pushed into stainless steel pipe, passed through the metering pump and squeezed out by the ring spinneret into a certain air gap followed by cooling water. At the moment, the phase separation occurred in homogeneous solution and the fine stream of solution solidified into hollow fiber membrane. Finally, the fiber membranes were winded in a rolling machine and PA6 hollow fiber gel membranes formed. The gel spinning system was assembled as shown in Fig. 14.

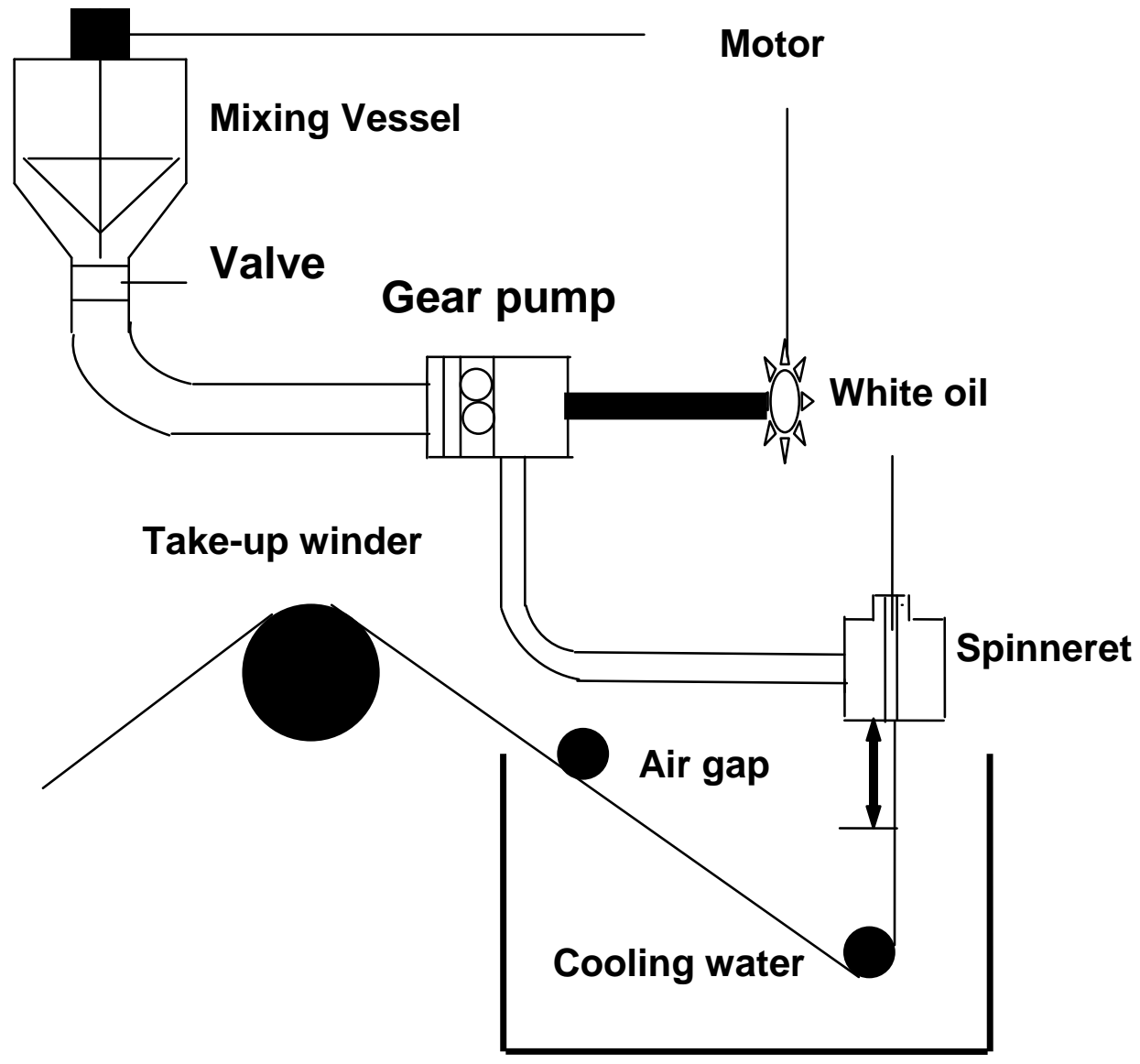

Fig. 14. Schematic diagram of spinning process. 
Tab. 2. The geometric parameters of samples.

\begin{tabular}{lcccc}
\hline Samples & $\mathrm{S} 1$ & $\mathrm{~S} 2$ & $\mathrm{~S} 3$ & $\mathrm{~S} 4$ \\
\hline PA6 weight ratio/\% & 35 & 40 & 50 & 55 \\
diluent weight ratio/\% & 65 & 60 & 50 & 45 \\
$\mathrm{CaCO}_{3}$ weight ratio/\% & 40 & 40 & 40 & 40 \\
(account for PA6) & & & & \\
outer-diameter/mm & 1.325 & 1.675 & 1.625 & 1.625 \\
inner-diameter/mm & 1.025 & 0.8 & 0.8 & 0.7 \\
spinning temperature/ ${ }^{\circ} \mathrm{C}$ & 200 & 200 & 210 & 210 \\
length of the air gap/cm & 7 & 7 & 8 & 8 \\
\hline
\end{tabular}

\section{Characterization of membranes}

\section{-SEM observations}

The porous samples were fractured in liquid nitrogen and then mounted on a sample support. The surfaces of the samples were coated with a gold layer. Quanta200 scanning electron microscope was used to observe the microstructure of the samples.

\section{-Pure water flux}

Pure water flux was measured with self-made water flux test device at $0.4 \mathrm{MPa}$ pressure. The flux was equilibrated for the passage of the first 15 min permeate whilst the following 15 min permeate was collected for calculating. Pure water flux was evaluated by eqn (1):

$$
J=\frac{V}{A t}
$$

where $J$ is pure water flux $\left(\mathrm{L} / \mathrm{m}^{2} \cdot \mathrm{h}\right), V$ the volume of penetration water $(\mathrm{L}), A$ the effective area of the membrane $\left(\mathrm{m}^{2}\right)$ and $t$ is the recorded time $(h)$. All the experiments have been conducted thrice to obtain the results presented in this study which were an average value.

\section{-Porosity}

The membrane porosity $(\varepsilon)$ was defined as the pores volume divided by the total volume of the porous membrane. It can be determined by eqn (2):

$$
\varepsilon=\frac{m_{0}-m_{3}}{m_{1}-\left(m_{2}-m_{0}\right)} \times 100 \%
$$

where $m_{3}$ is the dry membrane weight, $m_{0}$ is the wet membrane weight, $m_{1}$ is the weight of pycnometer full of water and $m_{2}$ is the weight of pycnometer after putting wet membrane into pycnometer full of water.

\section{Bubble point pore diameter}

The pore size of the hollow fiber was investigated by the bubble-point with gas permeation method. Nitrogen gas was forced to permeate from the inside to the 
outside of the hollow fibers, similar to that described by Piatkiewicz et al [14]. The transmembrane pressure drop was restricted within $86.50 \mathrm{PSI}$ in the test. At first, the membranes were immersed in ethanol for $4 \mathrm{~h}$ to ensure that all pores of the hollow fiber were filled with ethanol, and the relationship between the nitrogen flux through the wet hollow fiber and transmembrane pressure drop was measured by capillary flow porosimetry(US Laurel, CFP-1100- $A^{*}$ ).During the variation of transmembrane pressure drop from 0 to $86.50 \mathrm{PSI}$, the pressure at which nitrogen flux began to increase was considered as bubble point pressure. The relationship between pore size and pressure drop is given by Laplace equation:

$$
r=\frac{\sigma \cos \theta}{\Delta p}
$$

where $\sigma, \theta$ and $p$ represent surface tension of ethanol, contact angle between ethanol and the membrane, and pressure drop respectively. Prepare three samples for every experiment, and then take average value as reference.

\section{Crystallization}

Differential scanning calorimetry (NETZSCH, DSC200F3) was carried out with a heating rate of $10 \mathrm{~K} / \mathrm{min}$ in a temperature interval 298-523K.Melting heat $\Delta H$ was determined from the melting peak area. The degree of crystallinity was evaluated by eqn (4):

$$
\varnothing_{D S C}=\frac{\Delta H}{\Delta H_{100} \times V_{m}}
$$

$\Delta H_{100}=230 \mathrm{~J} / \mathrm{g}$ is crystallization heat for a $100 \%$ crystalline sample of PA6 [15]. $V_{m}$ is the mass fraction of PA6.

\section{Acknowledgements}

The authors gratefully acknowledge the financial support of the National Natural Science Foundation of China (20874073), National 863 (high-tech research and development) Program of China (2007AA030304) and Tianjin Science and Technology Key Support Plan (08ZCGYGX03700).

\section{References}

[1] Zeni, M.; Riveros, R.; de Souza, J.F.; Mello, K.; Meireles, C.; Filho, G.R. Desalination, 2008, 221, 294.

[2] Madaeni, S.S.; Ghaedi, A.M.; Rahimpour, A. Iran Polym J. 2006, 15, 275.

[3] Ding, H.Y.; Zhang, Q.; Tian, Y. J Appl Polym Sci. 2007, 104, 1523.

[4] Lloyd, D. R.; Kim, S. S.; Kinzer, K. E. J Membr Sci, 1991, 64, 1.

[5] Kim, S. S.; Lloyd, D. R. J Membr Sci. 1991, 64, 13.

[6] Zhou, J.; Zhang, H.; Wang, H.; Du, Q. J Membr Sci. 2009, 343, 104.

[7] Zhang, J.; Fu, J.; Wang, X. I, 2006,191, 151.

[8] Funk, C.V.; Beavers, B.L.; Lloyd, D.R. J Membr Sci. 2008, 325, 1.

[9] Matsuyama, H.; Maki, T.; Teramoto, M. J Membr Sci. 2002, 204, 323.

[10] Cui, Z-Y.; Xu, Y-Y.; Zhu, L-P. J Membr Sci. 2008, 325, 957.

[11] Moriya, A.; Maruyama, T.; Ohmukai, Y. J Membr Sci. 2009, 342, 307.

[12] Qiu, Y-R.; Rahman, N.A.; Matsuyama, H. Sep Purif Technol. 2008, 61, 1.

[13] Ding, H.; Tian, Y.; Wang, L.; Liu, B. J Appl Polym Sci. 2007,105, 3355. 
[14] Piatkiewicz, W.; Rosinsk,i S.; Lewinska, D.; Bukowski, J.; Judycki, W. J. Membr. Sci. 1999, 153, 91.

[15] Xenopoulos, A.; Clark, E. S. Nylon Plasitics Handbook. New York, Hanser Publ, 1995, 107.

[16] Li, N.; Xiao, C. Iran Polym J. 2009, 18, 479.

[17] Kim, W.K.; Char, K.; Kim, C. K. J Polym Sci: Part B: Polym Physics, 2000, 38, 3042.

[18] Zhang, C.; Zhu, B.; Ji, G.; Xu, Y. J Appl Polym Sci. 2006, 99, 2782.

[19] Zhou, J.; Zhang, H.; Wang, H.; Du, Q. J Membr Sci. 2009, 343, 104.

[20] Wang, J.; Xu, Z.; Xu, Y. J Appl Polym Sci. 2006,100, 2131.

[21] Chang-Fa, X. J Appl Polym Sci.1990, 41, 439.

[22] Hu, X-Y.; Xiao, C-F.; An, S-L. J Mater Sci. 2007, 42, 6234. 